\title{
Optimal Sizing of Grid-Tied Solar PV for Transmission Congestion Management in a Deregulated System using LMP Analysis
}

\author{
Malado Diallo. ${ }^{*}$, Livingstone Ngoo. ${ }^{2}$, Michael Saulo. ${ }^{3}$, and Benaissa Bekkouche. ${ }^{4}$ \\ ${ }^{1}$ Department of Electrical Engineering, Pan African University, Institute for Basic Sciences, Technology and Innovation, Kenya. \\ ${ }^{2}$ Department of Electrical Engineering, Multimedia University of Technology, Kenya. \\ ${ }^{3}$ Department of Electrical Engineering, Technical University of Mombasa, Mombasa, Kenya. \\ ${ }^{4}$ Department of Renewable Energy and Sustainable Development, University of Mostaganem, Algeria.
}

\begin{abstract}
In deregulated power system, it is desired to transmit power to every part of the network without any limits resulting from congestion and as a result avoiding inefficiencies in generation dispatch. In order to reduce congestion in the transmission lines, a new approach to manage transmission congestion and improve social welfare is proposed in this research. This approach consists of optimal sizing and placement of grid-tied solar PV system using LMP analysis for congestion management and maximization of social welfare. The LMP and congestion rent (CR) at each node of the system are obtained from the Lagrange multiplier associated with OPF formulation to determine the optimal location of solar power plant. With optimal sizing and placement, a grid-tied solar PV system has the ability to reduce power losses, improve voltage profile and power quality. Since solar power is a random and intermittent energy, the sizing of solar PV system is done by taking into account the power variation of the solar system. The results show that the proposed approach gives better results, reduced congestion in the system while maximizing social welfare is. The proposed methods are implemented on the modified IEEE 30-bus test system.
\end{abstract}

Keywords: Locational marginal pricing (LMP); social welfare (SW); congestion rent (CR) congestion management; solar PV; optimal power flow (OPF).

\section{INTRODUCTION}

In a deregulated power system, one drawback of transmission network is overloading. It is desirable to be able to transmit power to all parts of network without violating system security constraints. The electrical power that can be transmitted between two locations in a network is limited by several security criteria such as voltage limits, lines thermal limits and stability limits [1]. When power cannot be transmitted to parts of network because of the limits mentioned, the system is said to be congested [2].

Transmission congestion is a major problem and can lead to serious disruptions in the power system. Congestion is due to poor coordination between generation and transmission services and sudden increase in load demand. This increases the gap between supply and demand thus affecting social welfare negatively. Therefore, Transmission congestion has impact on the entire system as well as on the individual market participants i.e., sellers and buyers [3] [4]. Solutions to relieve congestion, generally referred to as congestion management schemes, are of interest to both system operators and planners [5]. One of the most important functions of independent system operators ("ISO") in the deregulated electrical system is congestion management.

Several methods have been proposed in the literature for congestion management. In [6], the proposed method for congestion management determines the optimal location of a distributed generator (DG) in a deregulated electrical grid using the basis of a bus impedance matrix (Z-bus-based contribution factors). According to [7], congestion can be alleviated by rescheduling the timing of actual emissions of generator energy, limiting the load and operating phase shifters or FACTS devices [7]. A congestion management technique integrating wind energy has been proposed in which the independent grid operator (ISO) is responsible for proposing the appropriate size and location for the implementation of the wind farm on the basis of the LMP price reduction [5]. An enhanced Shift Load Factor (SLF) based Line Outage Distribution Factor (LODF) LMP congestion management technique has been presented in paper [8]. The following paper [9] investigates the cost control problem of congestion management model Based on Ant Colony Algorithm in the real-time power systems. It is show 
that the model can significantly reduce the cost of electricity. Conventional optimization methods are used to manage congested power systems using FACTS devices as an alternative to efficiently minimize the power flows in the system especially during the heavy demands [10]. The use of FACTS devices helps improve power capability, lower system losses, and increase system stability by controlling power flows [10]. The literature [11] proposed a congestion management technique called DG based on Locational Marginal Price (LMP) schemes. This method places DG in the system to relieve congestion and minimizes generation costs.

In this paper, locational marginal price (LMP) will be used to determine the optimal location of grid-tied solar PV in a deregulated power system. The LMP of a site is defined as the marginal cost to provide an additional increase in MW capacity at the site without violating the safety limits of the system. This price reflects not only the marginal cost of energy production, but also its delivery. Due to the effects of transmission losses and congestion on the transmission system, LMPs can vary considerably from one place to another. The LMP is the sum of marginal energy costs, marginal losses and congestion [4].

The persistence of the congestion problem indicates that new generation capacity or additional transmission facilities are needed to manage congestion. Decentralised production sources or renewable energies can be of great value in a highly congested area where LMPs are higher than elsewhere [12].In this study, we use LMP analysis and congestion rent to locate the optimal placement of the solar power plant to relieve congestion in transmission line. While the installation of solar power plant at an optimal location in the congested system could effectively improve the voltage profile, power quality and reliability of the grid, it also ensures the maximization of social welfare and congestion management.

With regard to the sizing of solar power plant, a new challenge arises: the random and intermittent nature of solar power due to constant variation of irradiance and temperature. This means that the determined size of the solar power plant is actually the required output power from the point of view of the power system. However, the actual capacity of the solar power plant is not simply the same as the determined size. It is proposed here to calculate the actual capacity of the solar power plant based on probability density function methods (PDF). The proposed approach is evaluated in IEEE 30-bus test system.

The rest of the document is organized as follows. The problem formulation of the proposed approach is described in Section 2. The methodology is described in section 3. The optimal size and location of the solar power plant for congestion management are calculated for a test system in section 4 . The main contributions of this document are summarized in section 5 .

\section{PROBLEM FORMULATION}

\section{1. Problem formulation of social welfare maximization without solar power}

The objective of power systems operation and planning in deregulated power markets is to maximize the social welfare through minimizing total generation costs [13]. The social welfare ( $\mathrm{SW}$ ) is obtained as the benefit function $B_{D i}\left(P_{D i}\right)$ in $\$ / \mathrm{hr}$ of DISCOs/DSTs minus the cost function $C_{G i}\left(P_{G i}\right)$ in $\$ / \mathrm{hr}$ of a GENCO of GENCOs/GSTs. The formulation of the congestion management problem in deregulated power system is maximization of SW subject to system power balance and system transmission congestion (or security) constraints [6]. Mathematically, the congestion management problem can be formulated as follows [6]:

$\operatorname{Max} S W=\sum_{i=1}^{N D} B_{D i}\left(P_{D i}\right)-\sum_{i=1}^{N G} C_{G i}\left(P_{G i}\right)$

With:

$$
\begin{aligned}
& B_{D i}\left(P_{D i}\right)=a_{D i}+b_{D i} P_{D i}-c_{D i} P_{D i}^{2}(\$ / h r), \\
& C_{G i}\left(P_{G i}\right)=a_{G i}+b_{G i} P_{G i}+c_{G i} P_{G i}^{2}(\$ / h r),
\end{aligned}
$$

Where $P_{D i}, P_{G i}$ are the real power demand and generation of the $i^{\text {th }}$ DISCO and $i^{\text {th }}$ GENCO.

Subject to equality and inequality constraints and bounds on variables as follows.

1. Power balance constraints as given by DC load flow at all buses [6]:

$P_{G i}-P_{D i}-P=0$

With

$$
\begin{array}{cc}
P=\sum_{j=1}^{N} \frac{1}{x_{i j}}\left(\delta_{i}-\delta_{j}\right) & \forall i=1,2, \ldots, N ; i \neq j \\
P_{G i}-P_{D i}=\sum_{j=1}^{N} \frac{1}{x_{i j}}\left(\delta_{i}-\delta_{j}\right) & \forall i=1,2, \ldots, N ; i \neq j
\end{array}
$$

2. Transmission congestion constraints as given by line power flows are less than/equal to line overloading limits:

$P l_{i j} \leq P l_{i j}^{M a x} \forall i-j \in N l$ 
3. Bounds on variables as follows:

$$
\begin{array}{ll}
0 \leq P_{G i} \leq P_{G i}^{M a x} & \forall i \in N G \\
0 \leq P_{D i} \leq P_{D i}^{M a x} & \forall i \in N D \\
\delta_{i}^{\text {min }} \leq \delta_{i} \leq \delta_{i}^{\text {max }} \forall i=1,2, \ldots, N
\end{array}
$$

Where:

- $\quad N D, N G, N, N l$ are the number of DISCOs/DSTs, number of GENCOs/GSTs, number of system buses, and number of lines;

- $\delta_{i}$ is the bus voltage angle at the $i^{\text {th }}$ bus;

- $x_{i j}$ is the series inductive reactance of the line connected between buses $i-j$;

- $\quad P l_{i j}, P l_{i j}^{M a x}$ are the real power flow over the line connected between buses $i-j$ and its maximum limit;

- $\quad P_{G i}^{M a x}, P_{D i}^{M a x}$ are the maximum values of $P_{G i}$ and $P_{D i}$;

- $\quad P$ is the net active power injection at node $j$ and

- $\delta_{i}^{\text {min }}, \delta_{i}^{\text {max }}$ are the Minimum and maximum values of $\delta_{i}$.

The Lagrangian function of the optimization problem incorporating all constraints in the objective function formulated in [14] :

$$
\begin{gathered}
L=\sum_{i=1}^{N G}\left[C_{G i}\left(P_{G i}\right)-\mathrm{B}_{\mathrm{Di}}\left(\mathrm{P}_{\mathrm{Di}}\right)\right]+\sum_{j=1}^{N} \lambda_{P_{j}}\left(P-P_{G_{j}}+P_{D_{j}}\right) \\
+\sum_{i j=1}^{N l} \mu_{L_{i j}}\left(P l_{i j}-P l_{i j}^{M a x}\right)+\sum_{i=1}^{N G} \mu_{P_{G_{i}}}^{-}\left(P_{G_{i}}^{M i n}-P_{G_{i}}\right) \\
+\sum_{i=1}^{N G} \mu_{P_{G_{i}}}\left(P_{G_{i}}-P_{G_{i}}^{M a x}\right)+\sum_{j=1}^{N} \mu_{V_{j}}^{-}\left(V_{J}^{M i n}-V_{j}\right) \\
+\sum_{j=1}^{N} \mu_{V_{j}}^{+}\left(V_{j}-V_{J}^{M a x}\right)
\end{gathered}
$$

Where $\lambda$ and $\mu$ are vectors of Lagrangian multipliers, with $\lambda$ 's are associated with equality constraints and $\mu$ 's are associated with inequality constraints. The OPF solution is obtained from the Lagrangian multipliers method and this solution allows determining the LMP of each bus and the congestion rent of the transmission line.

\subsubsection{Locational Marginal Price (LMP) and Congestion Rent (CR)}

Locational marginal price (LMP) is the least cost required to supply the cost of the increment of power at a specific location in a given system [15]. LMP is the lowest possible bid (marginal cost at any location for supplying energy to one incremental MW of load. Major factors that affect LMP values are network topology, energy demand (load), availability of generators, bidding of generators (marginal costs) and binding transmission limits (congestion) [16]. LMP consists of three components: the price of loss, the price of energy and the price of congestion.

\section{LMP = generation marginal cost + cost of marginal losses + congestion cost}

Therefore, the spot price at each bus is determined specifically and the difference in LMPs between the two ends of a congested line is related to the extent of congestion and MW losses in this line [17]. If the injection (or extraction) power at a particular bus increases the total system losses, then the price of power at that location increases. Similarly, if any transmission line limit is binding, then corresponding $\mu_{L_{i, j}}$ will be non-zero and will have an impact on prices at all buses. If the injection (or extraction) power at a particular bus increases the flows across the congested interface, the spot price at that bus increases [18]. LMP value is obtain from Lagrangian multipliers and it can be written by three following parts [14]:

$L M P_{i}=\lambda_{P i}=\lambda+\lambda \frac{\partial P_{L}}{\partial P_{i}}+\sum_{i, j=1}^{N_{L}} \mu_{L_{i, j}} \frac{\partial P_{i, j}}{\partial P}$

$$
L M P_{i}=\lambda_{P i}=\lambda+\lambda_{L, i}+\lambda_{C, i}
$$

Similar to Eq. (12) for any other bus like j, LMP can be written:

$$
L M P_{j}=\lambda_{P j}=\lambda+\lambda_{L, j}+\lambda_{C, j}
$$

where,

- $\lambda$ is the marginal energy component at the reference bus which is same for all buses,

- $\quad \lambda_{L, i}=\lambda \frac{\partial P_{L}}{\partial P_{i}}$ is the marginal loss component and

- $\quad \lambda_{C, i}=\sum_{i, j=1}^{N_{L}} \mu_{L i, j} \frac{\partial P_{i, j}}{\partial P}$ is the congestion component.

By taking the spot price difference between two buses $i$ and $j$ it can be written [13]:

$$
\Delta \lambda_{P_{i j}}=\left(\lambda_{L, i}-\lambda_{L, j}\right)+\left(\lambda_{C, i}-\lambda_{C, j}\right)
$$

Equation (14) shows that the LMP difference between two buses of the system pertained two parts, marginal losses and the congestion between those buses. Since marginal energy component is the same for all buses in network it is not involved in nodal price difference. The congestion rent is calculated by [13].

$$
C R=\left|\Delta \lambda_{P_{i j}} * P_{i j}\right|
$$




\section{2.Probabilistic Determination of Solar Power Plant capacity}

Solar power depends on meteorological conditions such as irradiance, ambient temperature which are directly related to geographical location [19]. The output power from a solar panel depends mainly on the irradiance. Therefore, the power output for various irradiance values is to be estimated which requires proper functional model. The best adopted model is Beta Distribution Function. The historical data of solar irradiance is processed according to seasons in year and then it is utilised for modelling the Beta Distribution Function [20].

\subsubsection{Solar irradiance modelling}

A stochastic model [21] of Solar panel is constructed based on Beta Distribution Function. Beta distribution is considered to be the most suitable model for statistical representation of the Probability Density Function (PDF). The Solar irradiance distribution of the panel is given by [21]:

$$
f_{b}(s)=\frac{\Gamma(\alpha+\beta)}{\Gamma(\alpha) \Gamma(\beta)} s^{(\alpha-1)}(1-s)^{(\beta-1)}, 0 \leq s \leq 1 ; \alpha, \beta \geq 0
$$

$\beta=(1-\mu)\left(\frac{\mu(1+\mu)}{\sigma^{2}}\right), \quad \alpha=\frac{\mu \beta}{1-\mu}$

where $f_{b}(s)$ is Beta distribution function and $s$ is the random variable of solar irradiance $(\mathrm{kw} / \mathrm{m} 2), \alpha$ and $\beta$ are the parameters of the Beta distribution function. $\mu$ and $\sigma$ are the mean and standard deviation of $s$ for the corresponding time segment. $\Gamma(\mathrm{x})$ is the gamma function given by [22]:

$\Gamma(x)=\int_{0}^{\infty} t^{x-1} e^{-t} d t, \quad$ for $x>0$

\subsubsection{Power generation from solar PV array}

The expected output of solar PV is given in by [20]

$$
P(s)=P_{0}(s) \times f_{b}(s)
$$

The total output of the Solar PV array corresponding to specific time segment is given by

$T P_{\text {solar }}=\int_{0}^{1} P_{0}(s) \times f_{b}(s) d s$

where power generation $P_{0}(s)$ of panel at solar irradiance $s$ is given by

$$
P_{0}(s)=N \times F F \times V_{y} \times I_{y}
$$

where $\mathrm{N}$ is the total number of $\mathrm{PV}$ modules.
The voltage - current characteristics of a PV module for a given radiation level and ambient temperature are determined using the following relations given by [20].

$$
\begin{aligned}
& F F=\frac{V_{M P P T} \times I_{M P P T}}{V_{O C} \times I_{S C}} \\
& V_{y}=V_{O C}-K_{v} \times T_{c y} \\
& I_{y}=s\left[I_{S C}+K_{i}\left(T_{c y}-25\right)\right] \\
& T_{c y}=T_{A}+s\left(\frac{N_{O T}-20}{0.8}\right)
\end{aligned}
$$

where $F F$ is the fill factor, $V_{M P P T}, I_{M P P T}$ are the voltage and current maximum power point, $V_{o c}, I_{s c}$ are the open circuit voltage and short circuit current of PV module, $K_{v}$ and $\mathrm{K}_{\mathrm{i}}$ are the voltage temperature coefficient and current temperature coefficient, $\mathrm{T}_{\mathrm{A}}, \mathrm{T}_{\mathrm{CY}}, \mathrm{N}_{\mathrm{OT}}$ are the ambient temperature, $\mathrm{PV}$ cell temperature and Normal operating temperature respectively.

\subsection{Problem formulation of social welfare maximization with solar power}

Using Beta distribution function, the output of a solar panel is estimated and then the total output obtained for the entire solar power plant is calculated [20]. This power generated by the solar power plant is considered as negative demand and is integrated to the optimal placement in order to manage congestion and improve social welfare.

The objective function of social welfare (SW) maximization Equation (3) for congestion management problem is formulated, including the effect of solar. The social welfare (SW) will be formulated as:

$$
\operatorname{Max} S W=\sum_{i=1}^{N D} B_{D i}\left(P_{D i}\right)-\sum_{i=1}^{N G} C_{G i}\left(P_{G i}\right)-C\left(P_{\text {solar }}\right)
$$

Most non-linear optimization solver is based on minimization of the objective function. So, to formulate a minimization type of problem, above equation is multiplied by -1 .

$$
\operatorname{Min} \sum_{i=1}^{N G} C_{G i}\left(P_{G i}\right)-\sum_{i=1}^{N D} B_{D i}\left(P_{D i}\right)+C\left(P_{\text {solar }}\right)
$$

Note that the cost of solar PV C $\left(P_{\text {solar }}\right)$ should be free due to zero fuel cost of solar power generation, so the objective function remains the same as in Equation (3) but the equality Equation (5) and bounds on variables will be changed in consideration of grid-tied solar PV effect as follows.

1. Power balance constraints as given by DC load flow at all buses: 
For incorporating the solar energy into the exiting generation, the power generated by PV arrays is considered as a negative load and Equation (5) is updated as follows [20].

NewP $P_{D_{i}}=P_{D_{i}}-P_{\text {solar }}$

Therefor the power balance is given by:

$P_{G_{i}}-P_{D_{i}}-P_{\text {solar }}=\sum_{j=1}^{N} \frac{1}{x_{i j}}\left(\delta_{i}-\delta_{j}\right) \quad \forall i=1,2, \ldots, N ; i \neq j$

2. The bound on power generated by solar power is given by

$$
\mathbf{0} \leq \boldsymbol{P}_{P V k} \leq P_{P V}^{\max } \quad \forall k \in N
$$

Where $k$ is the bus location of solar power plant $\boldsymbol{P}_{\mathbf{P V k}}$ is the real power generated by solar at the $i^{\text {th }}$ bus, and $\boldsymbol{P}_{\boldsymbol{P V}}^{\max }$ is the rating of solar power used.

\section{METHODOLOGY}

The proposed methodologies are based on the analysis of the LMP and the congestion rent for the optimal placement of solar power plant and the density probability function is used for the sizing of grid-tied solar PV for congestion management and maximization of social welfare. First, in order to reduce the solution space and calculation costs, a list of candidate bus locations is provided.

Since buses with production capacity greater than demand probably have a low LMP, these are not potential locations for the location of solar power plant. In addition, if it is necessary to reduce the power of these buses $\left(P_{K}\right)$ to reduce congestion, increasing the output power of solar power plant is probably the best way to manage congestion and improve social welfare. Therefore, in order to reduce the solution space, buses are first examined using equation (31) in [13], if a bus does not have a generator or if its production capacity is less than its load, then it is a potential location for a solar power plant .

$$
P_{G_{k}} \leq P_{D_{k}}, k=1, \ldots N_{k}
$$

After the identification of the candidate buses for the installation of the solar power plant, OPF is carried out in the basic case for the maximization of social welfare. The prices are obtained as lagrangian multipliers of non-linear equality constraints. Since LMPs serve as a price indicator for both transmission losses and congestion, they should be an integrant part of any study on congestion management and the reduction of electricity costs (social welfare). The simple and appropriate method for the optimal placement of solar power plant is to determine the node with the highest LMP of the system.

Higher LMP implies a greater effect of active power flow equations of the node on total social welfare of the system. In other words, higher LMP implies higher the generation pressed by demand at that node. It thus provides indication that for the objective of social welfare maximization, injection of active power at that node will improve the net social welfare [2]. As the solar PV system is assumed to inject real power at a node, the node with highest LMP will have first priority for solar power plant placement [23].

In order to confirm the efficiency of the highest LMP method, the congestion rent calculation is performed for each transmission line for the identification of transmission congestion line then to determine the optimal location of solar power plant. The LMP difference is multiplied by the power transferred across the line, which gives the congestion rent on this line for a base case as indicated in equation (15). The line with the highest congestion rent represents the optimal location of solar power plant.

Once the optimal location of the solar power plant is found, a probabilistic study is carried out for the sizing of solar power plant. Since the output power of a solar panel depends mainly on the irradiance, the Beta distribution function is used to estimate the various irradiance values, and historical solar irradiance data are processed according to the seasons of the year (summer, spring and winter). Solar panel models are chosen to model the solar PV system and then the sizing is done taking into account the voltage of the bus where the solar power plant will be installed and the losses in the system. The optimal capacity of the solar power plant is then determined.

After the integration of the solar power plant, the OPF of the congestion management problem with solar energy is performed. In order to evaluate the effectiveness of the proposed method, a comparative analysis is carried out, the LMP and the congestion rent is evaluated without and with placement of solar power plant. The proposed congestion management problem is a non-linear programming problem and is solved with the help of optimization toolbox (using optimization function $f m \_o p f m$ ) in the MATLAB environment.

\section{RESULT AND DISCUSSION}

The methodology discussed above is simulated on the modified IEEE 30-bus system, which consists of 6 generators (GENCOs), 21 demands (DISCOs), and 41 transmission lines (shown in Appendix Figure 1). The test system is used to analyse the LMP and congestion rent to determine the optimal location of the grid-tied solar PV system to solve the congestion problem and maximize social welfare through the OPF using a Primal-dual Interior Point technique.

Bus-1 has been taken as a slack bus with its voltage adjusted to 1.1 (p.u), all the data given based on 100MVA and total demand of the system is $412 \mathrm{MW}$. The lines, buses and load data's of 
test system has been taken from [17], the bid prices by generators are given in Table 1 , where $a_{i}, b_{i}$, and $c_{i}$ are cost coefficients. $a_{i}$ and $b_{i}$ are a variable cost and $c_{i}$ is fixed cost of the real power generating unit.

Table 1. Generators operating costs and its limits

\begin{tabular}{cccccc}
\hline \hline Supplies & $P_{g}^{\text {min }}$ & $P_{g}^{\text {max }}$ & $a_{i}$ & $b_{i}$ & $c_{i}$ \\
Bus & $(\mathrm{MW})$ & $(\mathrm{MW})$ & $(\$ / \mathrm{h})$ & $(\$ / \mathrm{MWh})$ & $\left(\$ / \mathrm{MW}^{2} \mathrm{~h}\right)$ \\
\hline Bus1 & 50 & 200 & 0.00375 & 2 & 0.00 \\
Bus2 & 20 & 80 & 0.0175 & 1.75 & 0.00 \\
Bus5 & 15 & 50 & 0.0625 & 1 & 0.00 \\
Bus8 & 10 & 35 & 0.0083 & 3.25 & 0.00 \\
Bus11 & 10 & 30 & 0.025 & 3 & 0.00 \\
Bus13 & 12 & 40 & 0.025 & 3 & 0.00 \\
\hline \hline
\end{tabular}

\section{1. LMP and Congestion Rent analysis without solar power}

LMP and rent congestion are calculated to determine the optimal placement of solar power plant. Since generation buses have a lower LMP, to reduce solution space and calculation costs in this study we consider that load buses that potentially have higher LMPs and represent potential candidates for the integration of the solar power plant. From the simulation, we obtain the results of the optimal power flow (OPF) from which we find the value of the LMP at each node of the system as show in Table 2.

Table 2. Base case power dispatch with corresponding demand and LMP without Solar power

\begin{tabular}{ccccc}
\hline $\begin{array}{c}\text { Bus } \\
\mathrm{N}^{\circ}\end{array}$ & $\begin{array}{c}\mathrm{Pg} \\
{[\mathrm{MW}]}\end{array}$ & $\begin{array}{c}\mathrm{Pd} \\
{[\mathrm{MW}]}\end{array}$ & $\begin{array}{c}\text { LMP } \\
{[\$ / \mathrm{MWh}]}\end{array}$ & $\begin{array}{c}\mathrm{V} \\
{[\mathrm{p} . \mathrm{u} .]}\end{array}$ \\
\hline 1 & 200 & - & 5.6312 & 1.0997 \\
2 & 80 & 100 & 5.6731 & 1.0773 \\
3 & - & 99.7826 & 7.4246 & 0.9165 \\
4 & - & 86.6814 & 7.5967 & 0.9235 \\
5 & 50 & 91.7563 & 8.2146 & 0.9002 \\
6 & - & - & 7.7454 & 0.9435 \\
7 & - & 0.6357 & 8.0941 & 0.9164 \\
8 & 35 & 11.5382 & 7.8448 & 0.9429 \\
9 & - & - & 7.5517 & 1.0163 \\
10 & - & 8.8804 & 7.6624 & 1.0018 \\
11 & 30 & - & 7.4054 & 1.0997 \\
12 & - & 12.7240 & 7.5007 & 0.9911 \\
13 & 40 & - & 7.0798 & 1.0222
\end{tabular}

\begin{tabular}{ccccc}
14 & - & 0.0262 & 7.8276 & 0.9773 \\
15 & - & -0.0103 & 8.0184 & 0.9733 \\
16 & - & 0.1980 & 7.6799 & 0.9876 \\
17 & - & 0.2285 & 7.7412 & 0.9919 \\
18 & - & -0.0223 & 8.1428 & 0.9710 \\
19 & - & -0.0166 & 8.1431 & 0.9728 \\
20 & - & 0.0071 & 8.0340 & 0.9793 \\
21 & - & 0.1215 & 7.8106 & 0.9908 \\
22 & - & - & 7.8764 & 0.9885 \\
23 & - & -0.0572 & 8.5164 & 0.9605 \\
24 & - & -0.0749 & 9.0416 & 0.9519 \\
25 & - & - & 11.1852 & 0.9017 \\
26 & - & -0.1170 & 11.8882 & 0.8834 \\
27 & - & - & 12.2161 & 0.8796 \\
28 & - & - & 8.5042 & 0.9384 \\
29 & - & -0.1346 & 19.8449 & 0.8150 \\
$\mathbf{3 0}$ & - & $\mathbf{- 0 . 1 3 6 4}$ & $\mathbf{2 8 . 6 4 3 8}$ & $\mathbf{0 . 8 0 0 7}$ \\
\hline \hline Total & 435 & 412.0110 & & \\
\hline
\end{tabular}

The maximum power generation is $435 \mathrm{MW}$ without solar PV power plant in the grid. From Table 2, the highest LMP of the system to 28.6438 \$MWh is obtain at bus-30 with the lowest voltage magnitude of 0.8 (p.u.), bus-30 represents the weak bus of the system. Bus 1 is the slack bus with the lowest LMP of 5.6312 \$/MWh. For more illustration, LMP at each node of the system is shown in figure 1 .

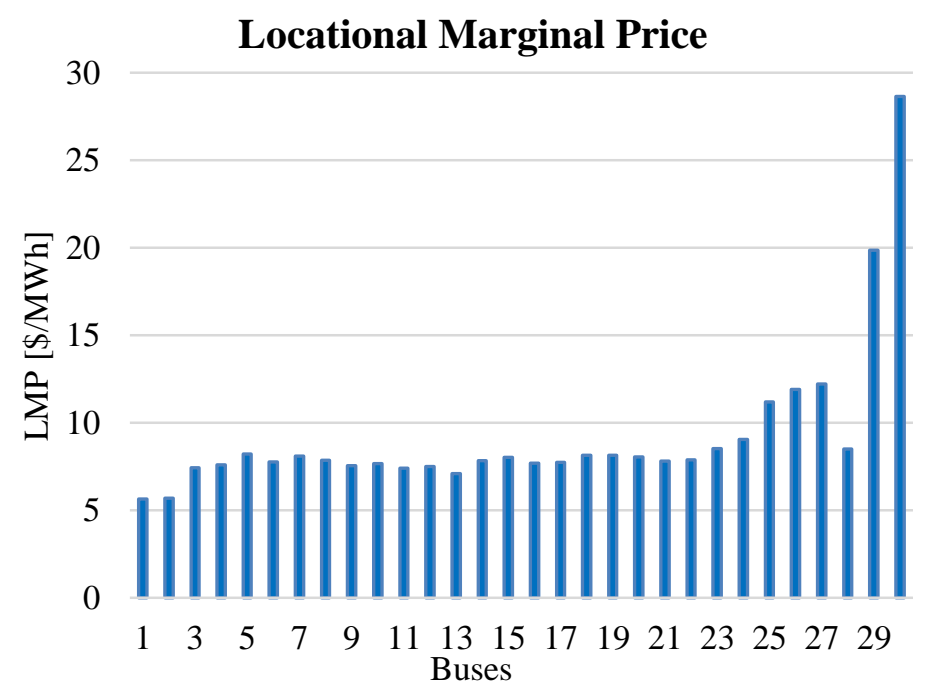

Figure 1. Locational marginal price at each node of the system

In order to confirm that bus-30 has the highest LMP value in the system, the congestion rent calculation is performed for each transmission line for the determination of the optimal location of solar power plant. The LMP difference is multiplied 
by the power transferred across the line, which gives the congestion rent on this line for a base case as indicated in equation (15). The line with the highest congestion rent represents the congested transmission line and it represents the optimal location of the solar power plant. Congestion rent analysis is shown in Figure 2 as follows.

\section{Congestion Rent $[\$ / h]$}

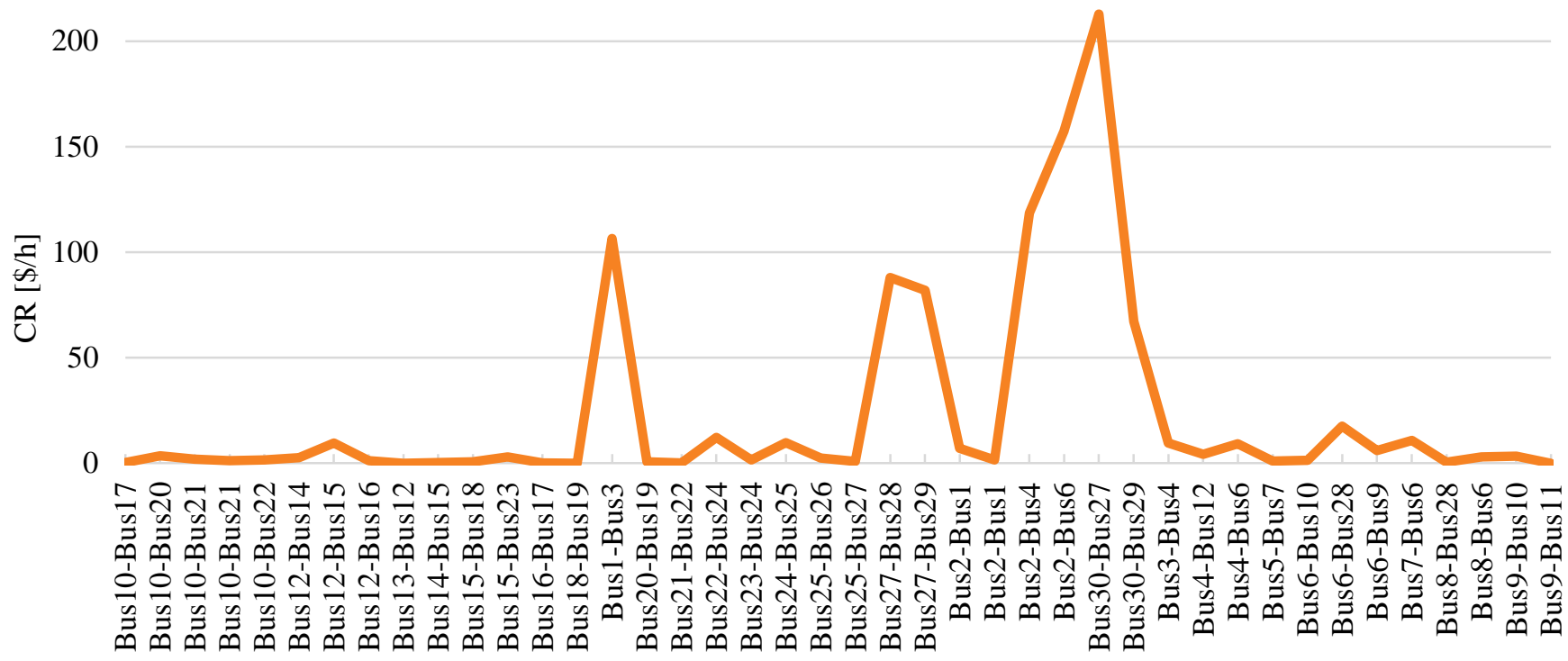

Transmission lines

Figure 2. Congestion rent at each line of the system

From Figure 2 it is obtain that the line between bus-27 and bus30 has the highest congestion rent to $212.8856 \$ / \mathrm{h}$. we can see that, this transmission line (from bus-27 to bus-30) is the most congested line follows by line (from bus-1 to bus-3). Therefore, by consider LMP analysis and congestion rent calculation, we conclude that bus-30 with highest LMP value and highest rent is the optimal placement of grid-tied solar PV system. Once the optimal location of the solar power plant is determined, the optimal sizing of the solar power plant is then performed using Probability Density Function (PDF).

\section{2. Optimal sizing of grid-tied solar power}

Solar power depends on meteorological conditions such as irradiance, ambient temperature which are directly related to geographical location [19]. For effective utilisation of PV arrays the characteristics should be seriously analysed. For this study, Sikasso region, which is located in Mali, is considered. The study period of one year is divided into three seasons Summer (March to June), Spring (July to October) and Winter (November to February). Mean $(\mu)$ and standard deviation $(\sigma)$ of solar irradiance at each season are calculated from the historical data [20] given in the appendix. The average value of variation in solar irradiance in Sikasso is shown in the appendix. It is observed that the irradiance is maximum in summer season.
For optimal sizing of solar power plant, Beta distribution function based on Probability Density Function (PDF) is used to model the solar panel. A matlab code is performed to calculate the total output power in the three seasons of year by using equations (16) to (25). Several solar panel with different capacities and different specification are used to determine the optimal solar panel that can get the necessary optimal output power of solar for maximizing the social welfare and at the same time reducing congestion in the transmission system. Solar panels $220 \mathrm{~W}, 300 \mathrm{~W}, 400 \mathrm{~W}$ and $500 \mathrm{~W}$ are used, their specification parameters are given in [20], [24], [25] and show in the appendix Table 2.

Matlab code calculate the total output power of solar power plant during summer season, spring season and winter season accordingly to the parameters of beta distribution function (mean $\mu$ and standard deviation $\sigma$ ) of solar irradiance. Table 3 give the result of solar output power at different season and with different capacity of solar panel.

Table 3 shows us that during summer season, solar irradiance is maximal as the power of solar power is proportional to the irradiance then the output power of solar power plant is also maximal during that period. In winter, the power plant produces the minimum of its capacity. At this level, we cannot say which capacity of output power is the optimal power that can maximize the social welfare and reduce the congestion. 
International Journal of Applied Engineering Research ISSN 0973-4562 Volume 14, Number 17 (2019) pp. 3598-3609

(C) Research India Publications. https://dx.doi.org/10.37622/IJAER/14.17.2019.3598-3609

Table 3. Solar output power capacities in MW

\begin{tabular}{cccc}
\hline \hline $\begin{array}{c}\text { Solar panel } \\
\text { capacity }\end{array}$ & Summer & Spring & Winter \\
\hline $220 \mathrm{~W}$ & 87.716 & 72.810 & 66.063 \\
$300 \mathrm{~W}$ & 120.54 & 99.913 & 90.598 \\
$400 \mathrm{~W}$ & 151.23 & 131.03 & 114.54 \\
$500 \mathrm{~W}$ & 198.83 & 164.98 & 149.67 \\
\hline \hline
\end{tabular}

To get the optimal size of solar power plant, the output powers of PV obtain previously are integrated to the grid at bus-30 and the OPF is performed for each output power of solar. The utility of grid-tied solar PV is to reduce the gaps between supplies and demands in the system, to reduce the losses and improve power quality. In term of cost, solar power after installation has free cost so that by introducing a solar power plant to the system the cost of power paid by customer will be reduce, therefore the social welfare will be maximized. Table 4 illustrates the cost of power paid for each capacity of solar power and the total losses of the system after connecting the solar power plant corresponding.

Table 4. Cost of power paid by the customer after grid-tied solar PV

\begin{tabular}{ccc}
\hline \hline $\begin{array}{c}\text { Solar Output } \\
\text { Power [MW] }\end{array}$ & $\begin{array}{c}\text { Pay } \\
{[\$ / \mathrm{h}]}\end{array}$ & $\begin{array}{c}\text { Total Losses } \\
{[\mathrm{MW}]}\end{array}$ \\
\hline 66.063 & 196.669786 & 20.721 \\
72.81 & 191.308307 & 20.185 \\
87.716 & 180.548847 & 19.11 \\
90.598 & 178.626551 & 18.919 \\
99.913 & 172.774892 & 18.337 \\
114.54 & 164.688911 & 17.531 \\
120.54 & 161.606882 & 17.257 \\
126.03 & 159.480786 & 17.143 \\
$\mathbf{1 3 1 . 0 3}$ & $\mathbf{1 5 8 . 0 9 6 5 3 2}$ & $\mathbf{1 7 . 1 3 5}$ \\
149.67 & 159.922223 & 17.911 \\
151.23 & 160.706420 & 18.033 \\
164.98 & 171.474949 & 19.525 \\
198.83 & 233.158246 & 26.806 \\
\hline \hline
\end{tabular}

The objective of the above analysis is to determine which output power is the optimal size of a solar power plant that maximizes social welfare by reducing the cost of power paid by customers. This analysis is illustrated in Figure 3, where we see that during the spring with $400 \mathrm{~W}$ solar panels used to build the solar power plant in this study, we obtain an output power of 131.03 MW. With a 131.03 MW solar power plant connected to the grid at the optimal location (bus-30) we obtain the lowest electricity cost of $158.096532 \$ / \mathrm{h}$ paid by consumers, which corresponds to the optimal size of the solar power plant to maximize the social welfare.

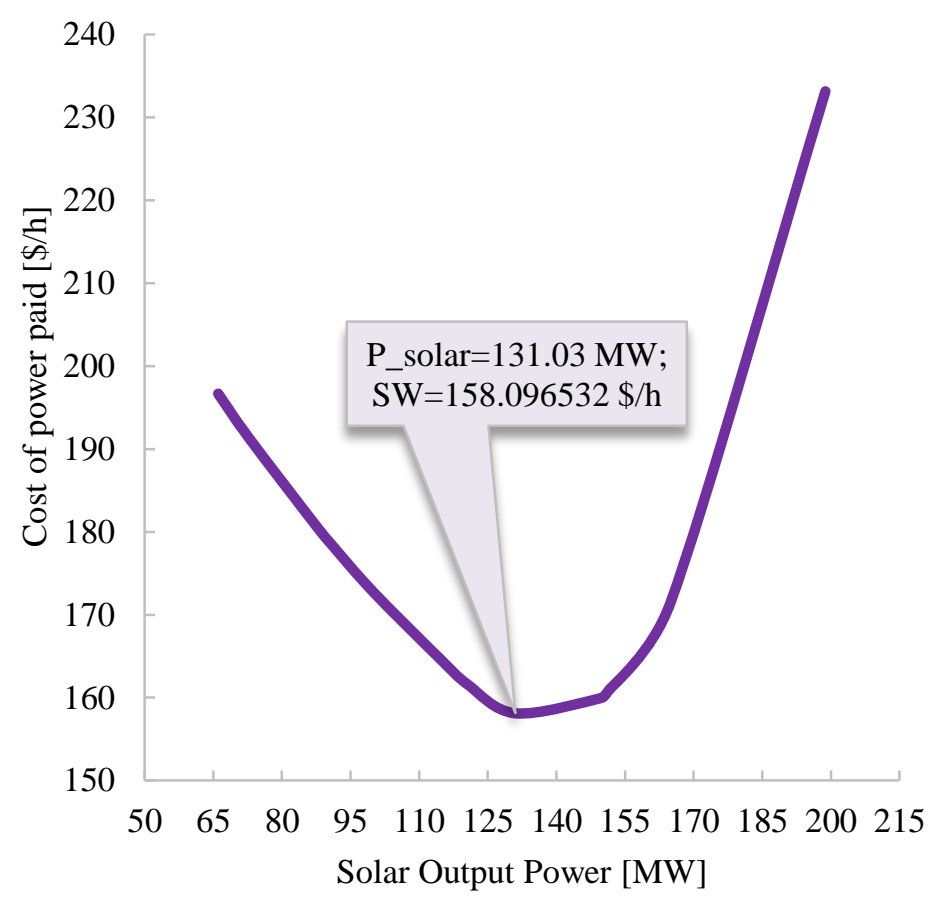

Figure 3. Characteristic cost of power paid - Solar output power

\section{3. Comparative LMP and Congestion Rent analysis of the system with and without solar power plant}

With the results obtained with grid-tied solar PV indicate an optimum of 131.03 MW of solar power. The comparative LMP and congestion rent analysis of the system is made with and without solar power plant integration and it is shown in figure 4 and figure 5 .

Without the solar power plant, the LMP at each node of the system varies considerably from $28.6438 \$ / \mathrm{h}$ to $5.6312 \$ / \mathrm{h}$ and the congestion rent is also too high at the line (bus 27 - bus 30). However, after connecting the solar power plant to the optimal location with the optimal size, the LMP at each node of the system became almost equal to $10.4374 \$ / \mathrm{h}$. We can say that the integration of the solar power plant has removed the marginal congestion component of the LMP and significantly reduced the marginal loss component of the LMP. Congestion rent also reduced considerably after grid-tied solar PV show in figure 5 . 


\section{LMP analysis with and without solar power plant}

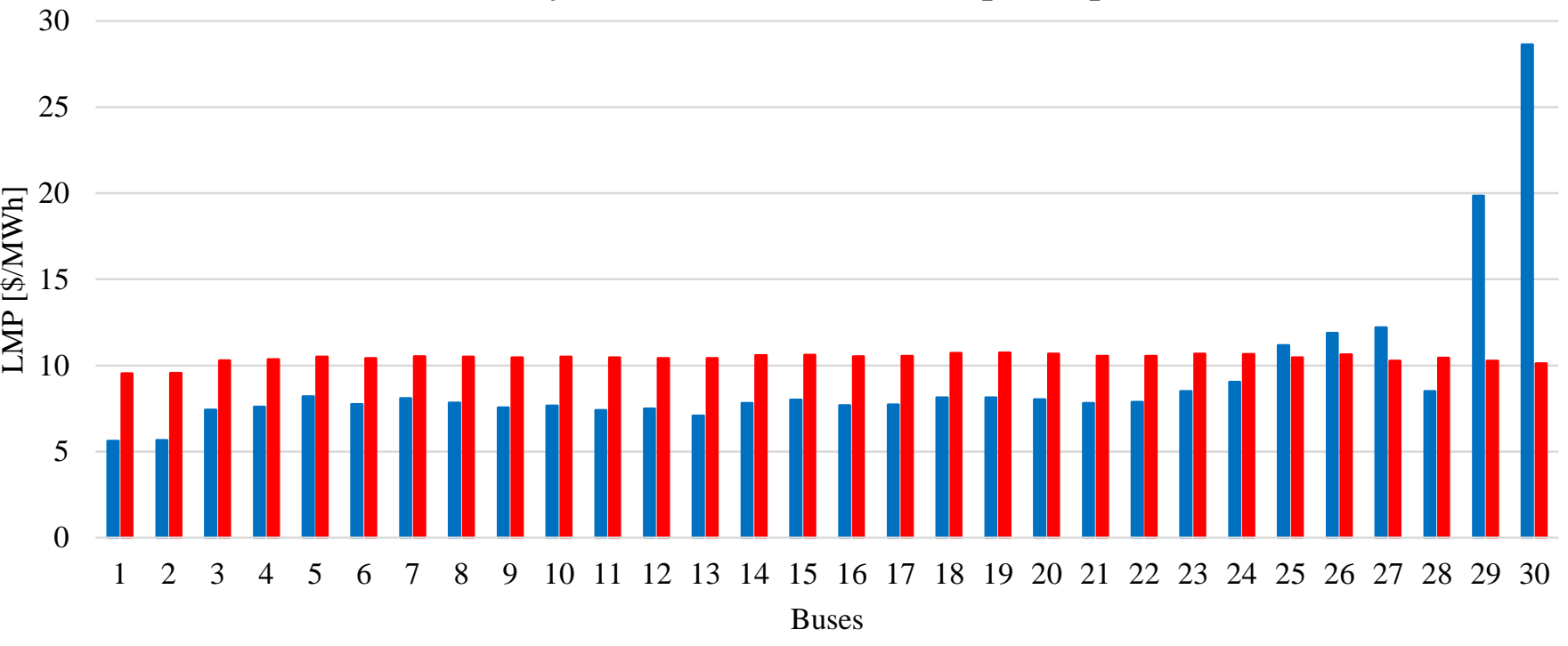

-LMP $[\$ / M W h]$ without solar power $\quad$ LMP $[\$ / M W h]$ with solar power

Figure 4. Comparison of LMP at each node of the system with and without solar power plant

\section{Congestion Rente analysis with and without solar power plant}

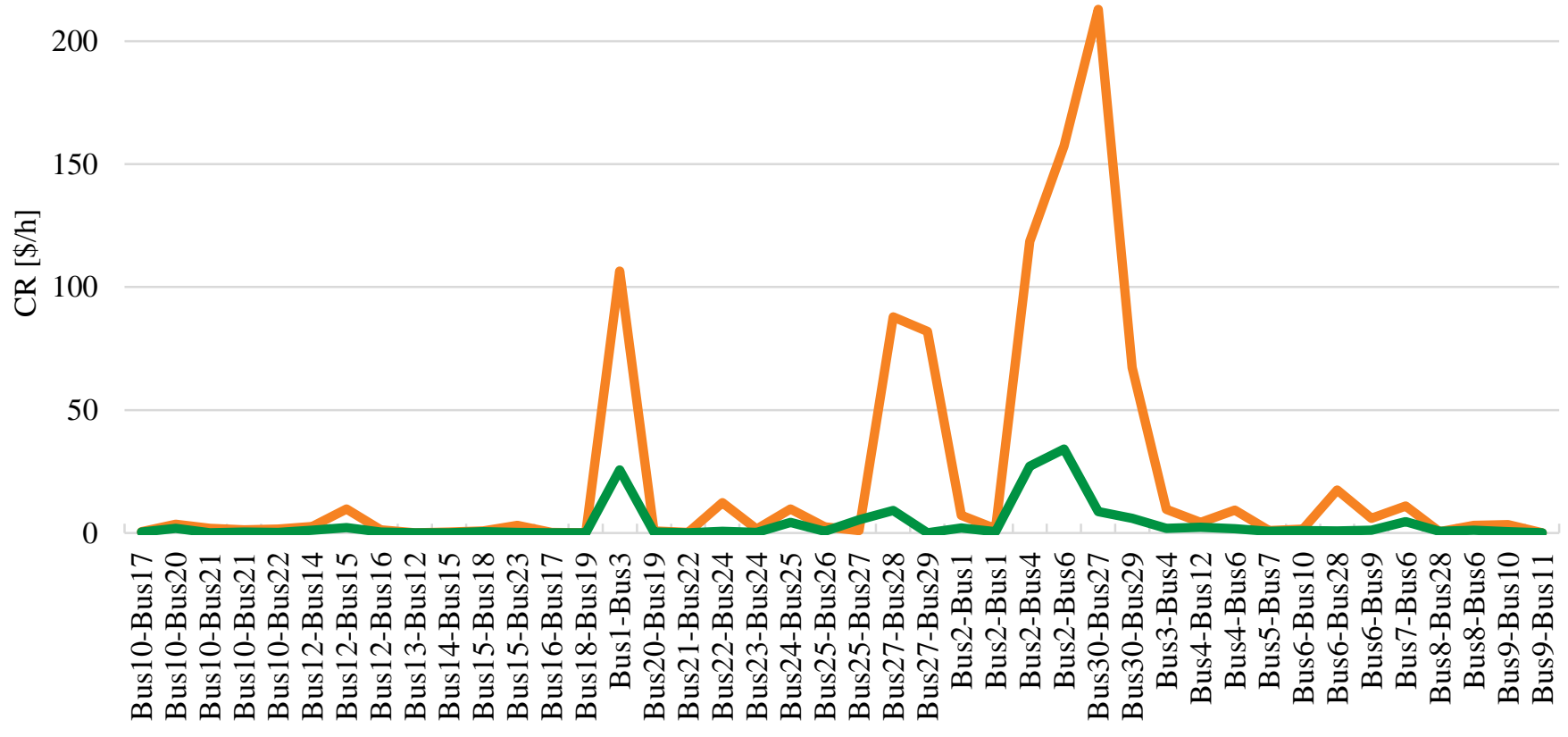

Transmission lines

$\longrightarrow \mathrm{CR}[\$ / \mathrm{h}]$ without solar power $\longrightarrow \mathrm{CR}[\$ / \mathrm{h}]$ with solar power

Figure 5. Comparison of congestion rent with and without solar power plant

As solar power injects real power, its placement has a direct effect of reducing LMP at the node where it is placed. The location of solar power plant has an overall impact on the power flow in the transmission system. The placement will therefore influence the LMPs at nodes other than the node where it is placed. Therefore, the penetration of solar power plant has a positive influence on all nodes of the system. All customers benefit from it based on the amount they receive. The need to pay for the same amount of electricity is reduced compared to the case without a solar PV plant.

In Table 5, a comparative review of social welfare with and without solar power plant is illustrated. The results show that 
in addition to reducing the LMP at the level of all buses in the system, there is a considerable maximization of social welfare by reducing the cost of power paid by customer and the problem of congestion on transport lines is reduced considerably.

Table 5. Social Welfare analysis

\begin{tabular}{lcc}
\hline \hline \multicolumn{1}{c}{ Output Parameters } & $\begin{array}{c}\text { Output (MW) } \\
\text { Without Solar }\end{array}$ & $\begin{array}{c}\text { Output (MW) } \\
\text { With Solar }\end{array}$ \\
\hline \hline Total losses & 37.361 & 17.143 \\
Bid losses & 22.476 & -17.888 \\
Total transaction level & 705.068041 & 746.28761 \\
\hline IMO PAY (\$/h) & 1215.42159 & 159.480786 \\
\hline \hline
\end{tabular}

\section{CONCLUSION}

The purpose of the research was to assess the impact of renewable energy resources mainly solar power on transmission congestion management in the deregulated power system and the maximization of social welfare using LMP analysis. LMP, which consists of a congestion component, as well as a fixed component and a loss component, plays an important role in the deregulated power market. It is used in a practical way for optimal placement of solar power plant in this study and congestion rent is used to confirm the effectiveness of the Highest LMP Method. Therefore, the measures necessary to maintain the lowest possible LMP values are a priority. The MATLAB-PSAT software's Optimal Power Flow (OPF) method is used and the LMP at each bus is determined by maximizing social welfare. The optimal sizing and location of solar power plant is formulated from the perspective of maximizing social welfare. System locations are examined to study the impact of renewable energy resources penetration on LMPs, so it is concluded that:

- Locally, solar energy has the effect of eliminating the marginal congestion component of the LMP, so making the LMP equal to each node of the system.

- The optimal dispatch from solar power is thus found to reduce the congestion rent and shadow prices associated with the line flow.

- Moreover, solar power with free cost is found to have better performance in terms of alleviating congestion in the network and maximising social welfare.

\section{REFERENCES}

[1] H. Ahmadi, M. Khanabadi, and H. Ghasemi, "Transmission system reconfiguration for congestion management ensuring transient and voltage stability," 2013 13th Int. Conf. Environ. Electr. Eng. EEEIC 2013 - Conf. Proc., pp. 22-26, 2013.

[2] M. Khanabadi, M. Doostizadeh, A. Esmaeilian, and M. Mohseninezhad, "Transmission congestion management through optimal distributed generation's sizing and placement," 2011 10th Int. Conf. Environ. Electr. Eng. EEEIC.EU 2011 - Conf. Proc., pp. 0-3, 2011.

[3] A. Swami, "Transmission Congestion Impacts on Electricity Market: An Overview," Int. J. Emerg. Technol. Adv. Eng., vol. 3, no. 8, 2013.

[4] A. Abirami and T. R. Manikandan, "Locational Marginal Pricing Approach for a Deregulated Electricity Market," Int. Res. J. Eng. Technol., vol. 2, no. $9,2015$.

[5] H. Ahmadi and H. Lesani, "Transmission congestion management through lmp difference minimization: A renewable energy placement case study," Arab. J. Sci. Eng., vol. 39, no. 3, pp. 1963-1969, 2013.

[6] K. Singh, V. K. Yadav, N. P. Padhy, and J. Sharma, "Congestion management considering optimal placement of distributed generator in deregulated power system networks," Electr. Power Components Syst., vol. 42, no. 1, pp. 13-22, 2014.

[7] M. N. Rothbard, "Power \& Market," vol. 1, no. 3, pp. 421-426, 100AD.

[8] K. B. R. Kumar and S. C. Mohan, "LMP Congestion Management Using Enhanced STF-LODF in Deregulated Power System," Sci. Res. Publ., no. 7, pp. 2489-2498, 2016.

[9] B. Liu, J. Kang, N. Jiang, and Y. Jing, "Cost Control of the Transmission Congestion Management in Electricity Systems Based on Ant Colony Algorithm," Energy Power Eng., no. 3, pp. 17-23, 2011.

[10] H. Patel and R. Paliwal, "Congestion Management in Deregulated Power System using FACTS Devices," vol. 8, no. 2, pp. 175-184, 2015.

[11] M. Sarwar and A. S. Siddiqui, "Congestion Management in Deregulated Electricity Market Using Distributed Generation," IEEE INDICON 2015, pp. 1$5,2015$.

[12] Kankar Bhattacharya, M. H. J. Bollen, and J. E. Daalder, Operation of Restructured Power Systems, vol. 39, no. 5. 2001.

[13] M. Afkousi-Paqaleh, A. Abbaspour-Tehrani Fard, and M. Rashidinejad, "Distributed generation placement for congestion management considering economic and financial issues," Electr. Eng., vol. 92, no. 6, pp. 193201, 2010. 
[14] D. Gautam and M. Nadarajah, "Influence of distributed generation on congestion and LMP in competitive electricity market," Int. J. Electr. Comput. Energ. Electron. Commun. Eng., vol. 4, no. 3, pp. 822-829, 2010.

[15] S. Padmini and B. Sahoo, "Analysis of LMP in a Competitive Electricity Market," Int. J. Pure Appl. Math., vol. 118, no. 24, pp. 1-7, 2018.

[16] I. Leevongwat, P. Rastgoufard, and E. J. Kaminsky, "Status of deregulation and locational marginal pricing in power markets," Proc. Annu. Southeast. Symp. Syst. Theory, no. 3, pp. 193-197, 2008.

[17] N. C. Abdullah Urkmez, "DETERMINING SPOT PRICE AND ECONOMIC DISPATCH," vol. 15, no. 1, pp. 25-33, 2010.

[18] M. Shahidehpour, H. Yamin, and Z. Li, Market Operations in Electric Power Systems: Forecasting, Scheduling and Risk Management. 2002.

[19] P. Kayal and C. K. Chanda, "Optimal mix of solar and wind distributed generations considering performance improvement of electrical distribution network," Renew. Energy, vol. 75, pp. 173-186, 2015.
[20] V. Suresh and S. Sreejith, "Economic Dispatch and Cost Analysis on a Power System Network Interconnected With Solar Farm," Int. J. Renew. Energy Rsearch, vol. 5, no. 4, 2015.

[21] V. Suresh and S. Sreejith, "Reserve Constrained Economic Dispatch Incorporating Solar Farm using Particle Swarm Optimization," vol. 6, no. 1, 2016.

[22] P. Sebah and X. Gourdon, "Introduction to the Gamma Function," vol. 0, no. 1, pp. 1-20, 2002.

[23] D. Gautam and N. Mithulananthan, "Optimal DG placement in deregulated electricity market," Electr. Power Syst. Res., vol. 77, no. 12, pp. 1627-1636, 2007.

[24] A. Resistance, "300 W - 320 W Poly-crystalline Solar Module," www.sunceco.com. .

[25] K. M. Bs and E. N. Photovoltaic, "LG400N2W-V5 I LG395N2W-V5 400w / 395w," 2016. .

[26] "Longitude, latitude, GPS coordinates of Mali," www.gps-longitude-latitude.net/coordonnees-gps-demali. .

\section{APPENDICES}

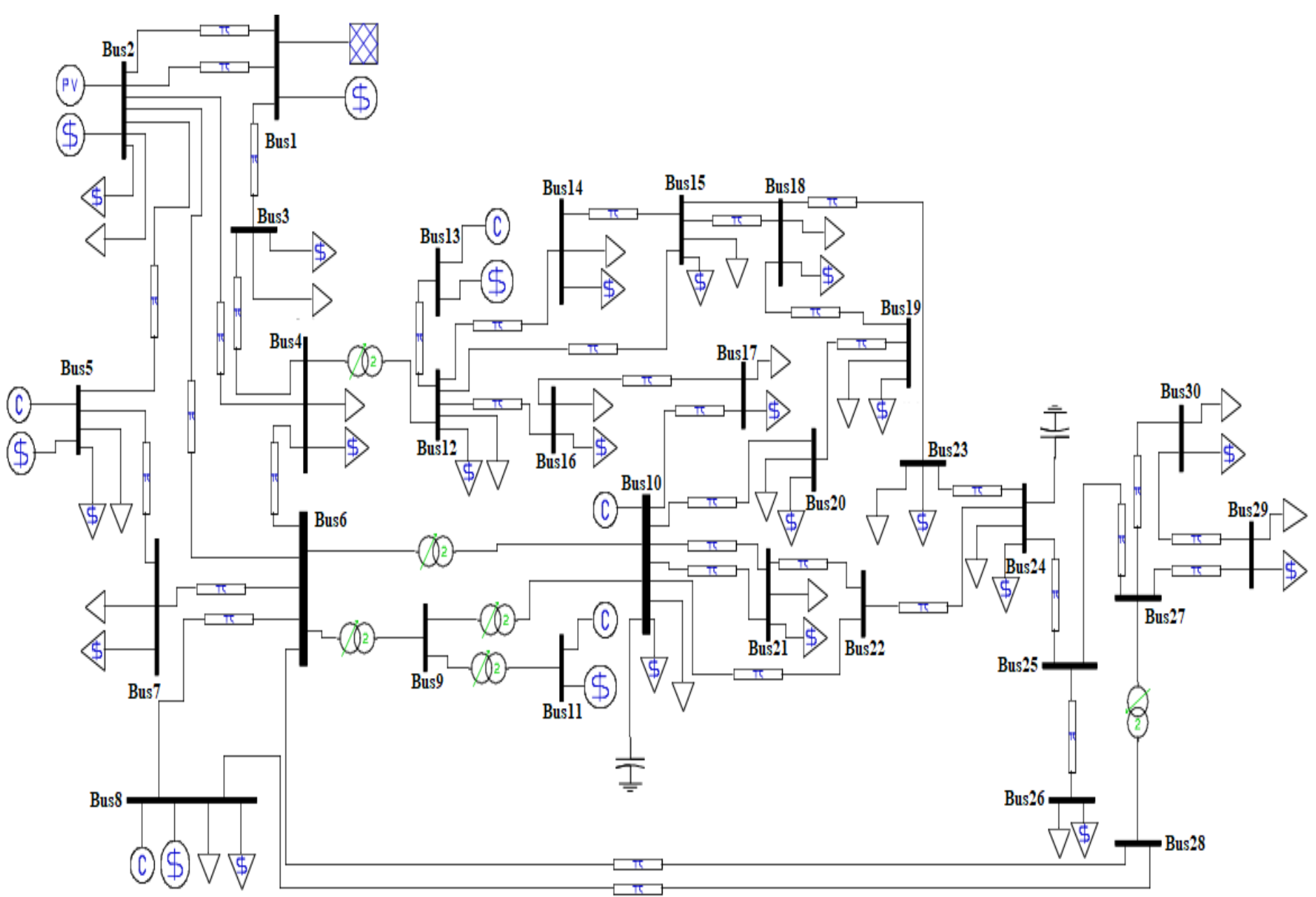


International Journal of Applied Engineering Research ISSN 0973-4562 Volume 14, Number 17 (2019) pp. 3598-3609 (C) Research India Publications. https://dx.doi.org/10.37622/IJAER/14.17.2019.3598-3609

Figure A.1. IEEE 30-Bus System

Table A.1. Specifications of $220 \mathrm{~W}, 300 \mathrm{~W}, 400 \mathrm{~W}$ and $500 \mathrm{~W}$ solar panel [20], [24], [25]

\begin{tabular}{|c|c|c|c|c|}
\hline Parameter & $220 \mathrm{~W}$ & $300 \mathrm{~W}$ & 400W & $500 \mathrm{~W}$ \\
\hline Maximum Power Point Voltage, $\mathrm{V}_{\text {MPPT }}[\mathrm{V}]$ & 28.36 & 37.23 & 40.6 & 48.63 \\
\hline Maximum Power Point Current, $\mathrm{I}_{\mathrm{MPPT}}[\mathrm{A}]$ & 7.76 & 8.06 & 9.86 & 10.28 \\
\hline Open Circuit Voltage, $\mathrm{V}_{\mathrm{OC}}[\mathrm{V}]$ & 36.96 & 44.71 & 49.3 & 58.95 \\
\hline Short Circuit Current, ISC $[\mathrm{A}]$ & 8.38 & 8.947 & 10.47 & 10.87 \\
\hline Nominal Operating Temperature, $\mathrm{N}_{\mathrm{OT}}\left[{ }^{\circ} \mathrm{C}\right]$ & 43 & 47 & 44 & 45 \\
\hline Ambient Temperature, $\mathrm{T}_{\mathrm{A}}\left[{ }^{\circ} \mathrm{C}\right]$ & 30.76 & 30.76 & 30.76 & 30.76 \\
\hline Voltage Temperature Coefficient, $\mathrm{K}_{\mathrm{v}}\left[\mathrm{V} /{ }^{\circ} \mathrm{C}\right]$ & -0.1278 & -0.1520 & -0.1282 & -0.1945 \\
\hline Current Temperature Coefficient, $\mathrm{K}_{\mathrm{i}}\left[\mathrm{A} /{ }^{\circ} \mathrm{C}\right]$ & 0.00545 & 0.004473 & 0.002094 & 0.006304 \\
\hline Total number of PV modules & 350000 & 350000 & 350000 & 350000 \\
\hline
\end{tabular}

Table A.2. Beta Distribution Function for Solar Irradiance Modeling [20]

\begin{tabular}{cccc}
\hline \hline Parameter & Summer & Spring & Winter \\
\hline Mean $(\mu)$ & 0.9302 & 0.7834 & 0.7152 \\
$\begin{array}{c}\text { Standard } \\
\text { Deviation }(\sigma)\end{array}$ & 0.1088 & 0.1772 & 0.2402 \\
\hline \hline
\end{tabular}

\section{Irradiances $\left[\mathrm{KW} / \mathrm{m}^{2}\right]$}

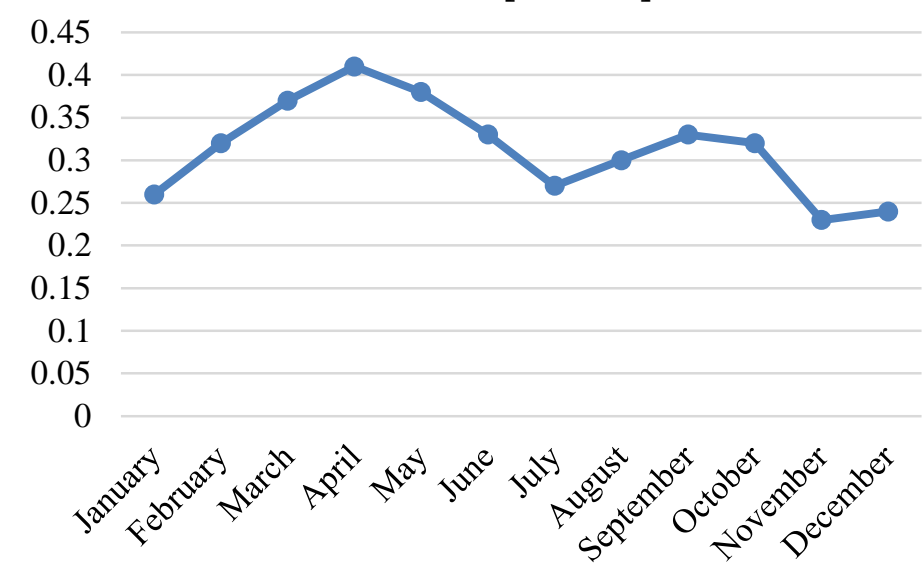

Figure A.2. Monthly variation of solar irradiation (KW/m2) in Sikasso region of Mali (17 34' 14.491" N $3^{\circ} 59^{\prime} 46.198^{\prime \prime}$

W) [26] 